\section{P038 HIV HOME/SELF-TESTING: A PILOT PROJECT AND SERVICE EVALUATION}

William Gibson*, Rachel Challenor, Zoe Warwick. Genitourinary Medicine Department, Derriford Hospital, Plymouth, UK

\subsection{6/sextrans-2016-052718.92}

Background/introduction Early HIV diagnosis prevents morbidity, mortality and transmission. UK 2014 figures show 40\% of new diagnoses were "late" and estimate an HIV positive population of 103,700 , with $17 \%$ remaining undiagnosed. Innovative testing approaches may help. Home/self-testing kits became available for UK purchase in April 2015. We describe a free online HIV home/self-testing project.

Aim(s)/objectives To determine feasibility/acceptability of HIV home/self-testing

Methods OraQuick Advance HIV1/2 Rapid Antibody Tests (using oral fluid for immediate self-testing) were requested online by individuals who confirmed studying the testing information and demonstration video. Postal kits included a username/password to allow completion of a feedback form, plus an out-of-hours mobile number for immediate support. $£ 282.28$ was spent on targeted Facebook advertising. (OraQuick Advance is not a CE marked home/self-testing kit. The MHRA were consulted and due to particular specifics of our programme an additional CE mark/formal notification was not required.)

Results Between 21/05/2015-08/02/2016, 513 kits were posted [394 (77\%) males, 119 (23\%) females; 352 (72\%) urban, 135 $(28 \%)$ rural]. Two new HIV diagnoses were identified $(2 / 513=$ 3.9/1000, compared with 1.9/1000 overall UK HIV prevalence, 2014). Partner notification produced one further HIV diagnosis. Ninety-eight (19\%) feedback forms were completed; 19 females/ 79 males. Of the 79 males, 58 (73\%) were men who have sex with men (MSM). Forty-six (47\%) had never tested previously; 25/58 (37\%) MSM had never tested. When asked why they chose this test, 26 said fast result, five no blood required and 67 no appointment/consultation.

Discussion/conclusion HIV home/self-testing is highly acceptable to those choosing it and can reach previously untested individuals.

\section{P039 USING PSYCHOSOCIAL AND SOCIO-DEMOGRAPHIC CORRELATES OF SEXUAL RISK AMONG WOMEN IN BRITAIN, TO TARGET SERVICES IN PRIMARY CARE: EVIDENCE FROM NATSAL-3}

\footnotetext{
${ }^{1,4}$ Natalie Edelman, ${ }^{1,3}$ Jackie Cassell ${ }^{*},{ }^{2}$ Richard de Visser, ${ }^{3}$ Catherine Mercer. ${ }^{1}$ Brighton \& Sussex Medical School, Brighton \& Hove, East Sussex, UKi ${ }^{2}$ University of Sussex, Brighton \& Hove, East Sussex, UK; ${ }^{3}$ University College London, London, UK; ${ }^{4}$ University of Brighton, Brighton \& Hove, East Sussex, UK
}

\subsection{6/sextrans-2016-052718.93}

Background In primary care settings it can be difficult to identify which women would benefit from contraceptive advice and supply (CAS) and sexually transmitted infection (STI) testing without asking sensitive questions about sexual behaviour. Psychosocial and socio-demographic questions may offer an acceptable alternative.

Aim To identify psychosocial and socio-demographic factors associated with reporting key sexual risk behaviours among women aged 16-44 years in the British general population.

Methods We analysed data from 4,911 heterosexually-active women aged 16-44 years, who participated in Natsal-3, undertaken 2010-2012. Using multivariable regression we explored associations between the available psychosocial and socio-demographic variables and reporting of 3 key sexual behaviours indicative of clinical need: $2+$ partners in the last year (2PP); non-use of condoms with $2+$ partners in the last year (2PPNC); non-use of condoms at first sex with most recent partner (FSNC).

Results After adjustment, weekly binge drinking (6+ units on one occasion), early sexual debut ( $<16$ years), younger age and renting (rather than owning) a home, remained associated with 2PP, 2PPNC and FSNC. Sexual identity and partner ethnicity were not associated with any of these behaviours. Current relationship status and reporting drug use (ever) were associated with 2 PP and 2PPNC but not with FSNC.

Discussion These analyses indicate psychosocial factors and socio-demographic factors may be useful in targeting CAS and STI testing. A large cross-sectional survey is now underway determine the extent of sexual risk explained by these factors among women presenting in primary care and their acceptability in those settings.

\section{P040 REDUCING THE LATE DIAGNOSIS OF HIV - WHERE ARE WE? AN EXPERIENCE FROM A COUNTY PERSPECTIVE}

${ }^{1}$ Richard Healy*, ${ }^{2}$ Leela Sanmani, ${ }^{1}$ Sophie Wallace, ${ }^{1}$ Catherine Jordan. ${ }^{1}$ Hampshire Hospitals NHS Foundation Trust, Winchester, Hampshire, UK; ${ }^{2}$ Solent NHS Trust, Hampshire, UK

\subsection{6/sextrans-2016-052718.94}

Background/Introduction HIV is a treatable medical condition, and death rates are similar to other long term conditions if the patient is diagnosed early enough for anti-retroviral therapy to have any meaningful effect and if the patient is adherent to their antiretroviral therapy. A late diagnosis is defined as a new HIV diagnosis with a CD4 count of $<350 \mathrm{cells} / \mathrm{mm}^{3}$, or an AIDSdefining illness.

Aim(s)/objectives Identify the numbers of late HIV diagnoses made over a five year period in a county with low prevalence. Educate hospital junior doctors \& GPs about the consequences of a late diagnosis of and when to test for HIV.

Methods The numbers of positive HIV tests were obtained, plus the patients' CD4 count at the point of a positive HIV test over a five year period. Patients were included or excluded based on the following criteria. Included: over 18; new diagnosis of HIV within secondary care; CD4 count <350/AIDS defining illness. Excluded: antenatal testing, occupational health test; GP testing. Results Fourteen patients identified. 12/14 were heterosexual white British males 11 of whom were diagnosed in hospital and mostly admitted under the acute medics. CD4 counts ranged from 0.01 to 475 with a mean count of 224 cells $/ \mathrm{mm}^{3}$.

Discussion/conclusion As a direct result of the talks delivered presenting the findings of the project, at the time of writing, two major changes in practice have occurred and there is closer collaboration between the hospital physicians, microbiology lab and the HIV consultants. A poster has been designed and is now found in numerous hospital sites.

\section{P041 2 PAEDIATRIC CASES OF HIV RELATED COMPLICATIONS IN SOUTHERN AFRICA}

Suzanne Kidd*, Alastair Findlay. No affliation, Glasgow, UK 
Background/introduction Southern Africa has some of the highest rates of HIV with a prevalence of over $10 \%$ in the adult population. As we enter the second decade of the epidemic over 17.1 million people in southern and eastern Africa live with the disease. In Zambia around 100,000 children under the age of 14 and in Malawi an estimated 170, 000 children have HIV.

Aim(s)/objectives Case study of 2 paediatric patients in Southern Africa with diagnosis of HIV related complications.

Methods Individual cases were examined and followed up.

Results An 8 year old girl, is seen in rural Zambia with new diagnosis of HIV, moderate malnutrition, septic wounds and cough. She lives far from a rural hospital and during wet season is unable to cross the river to attend follow up. A 14 year old boy in rural Malawi is seen with severe malnutrition, HIV treatment failure after late diagnosis, chronic abdominal pain due to 3TC pancreatitis and new neurology. The family refuse to attend the palliative care team at central hospital.

Discussion/conclusion Zambia currently has an estimated ART coverage of $72 \%$. Whilst this seems like excellent progress the child vs adult breakdown shows that only $26 \%$ of children with HIV have access to treatment compared to $84 \%$ of adults. In Malawi $51 \%$ of adults with HIV are on ART but only $30 \%$ of children receive therapy and $30 \%$ of paediatric cases receive a diagnosis of HIV within first 2 months of life. These cases explore the inequalities that children face with late diagnosis of HIV.

\section{P042 MSM SCREENING IN SAUNAS - IS IT WORTH IT?}

Lee Portas*, Adrian Langham, Ruth Taylor. Nottingham University Hospitals NHS Trust, Nottingham, UK

\subsection{6/sextrans-2016-052718.96}

Background Commissioners requested STI screening for MSMs attending male-only saunas in an effort to reduce HIV late diagnosis and engage hard-to-reach clients. Similar schemes have been successfully described elsewhere.

Aim Examine success of sexual health screening (SHS) and health promotion for 'high risk' MSM in saunas. We examined infection rate and proportion of individuals who were not accessing services elsewhere.

Methods Two saunas were visited monthly over 16 months by senior nursing staff. All attendees were offered a full SHS (HIV, STS, Hep B, GC, CT) and safer sex advice. Symptomatic individuals were signposted to main GUM clinic. We collected demographics and data on previous clinic attendance.

Results Results are outlined in Table 1. One symptomatic patient was signposted to the GUM clinic. Health promotion was provided to all.

\begin{tabular}{lllllll}
\multicolumn{6}{l}{ Abstract P042 Table 1} & \multicolumn{4}{l}{ MAM screening in saunas } \\
\hline $\begin{array}{llllll}\text { Total } \\
\text { Screened }\end{array}$ & $\begin{array}{l}\text { Age range } \\
\text { (yrs) }\end{array}$ & $\begin{array}{l}\text { Accessed } \\
\text { mainstream } \\
\text { services }\end{array}$ & Sexuality & $\begin{array}{l}\text { HIV/STS } \\
\text { testing }\end{array}$ & Positive results \\
\hline 30 & $22-76$ & $19(63 \%)$ & 26 Gay & $26(87 \%)$ & Chlamydia & 0 \\
& $($ mean 50) & & $(87 \%)$ & & Gonorhoea & 3 \\
& & 4 Bisexual & & HIV & $(10 \%)$ \\
& & $(13 \%)$ & & Syphilis & 0 \\
\hline
\end{tabular}

Discussion 64 hours of staff time were used (total cost $£ 2,632$ not including lab costs). Small numbers were seen, with an overall $10 \%$ positivity rate for STIs and no new HIV diagnoses. Many regular attendees declined repeat screening as they perceived themselves to be at low risk. We concluded that supplying condoms/lubrication and prominently displaying health promotion literature was a more effective way of engaging with this group in terms of both time $\&$ cost.

\section{P043 FLOW CYTOMETRIC CELL COUNTS: NOT PERFECT? (HOW GETTING A CALCULATOR OUT CAN SUGGEST AN ANOMALOUS RESULT)}

${ }^{1}$ Rebecca Thomson-Glover*, ${ }^{1}$ Colm O'Mahony, ${ }^{2}$ James Darroch. ${ }^{1}$ Countess of Chester NHS Foundation Trust, Chester, UK; ${ }^{2}$ Royal Liverpool University Hospital NHS Trust, Liverpool, UK

10.1136/sextrans-2016-052718.97

Background/introduction HIV patients have their CD4 counts measured regularly using flow cytometry, 'single platform' measurement being the current standard. Recently, two HIV patients attending for routine follow up blood tests showed unexpectedly low CD4 counts compared to previous results. Using the patients' total lymphocyte counts (obtained from contemporaneous testing on a haematology analyser) and CD4\% (from the flow cytometry report), we calculated a more expected result. This prompted a review of our CD4 counts comparing single and dual platform results.

Aim(s)/objectives To identify any anomalous results when comparing flow to calculated CD4s.

Methods Fifty-nine CD4 counts from 38 HIV patients $(27$ males and 11 females) attending clinic for routine bloods from 18/01/ 2015 to $09 / 02 / 2016$ were reviewed.

Results The table shows the comparison between the dual platform CD4 and the single platform CD4. The two patients that triggered the query are in green (male) and red (female). The sequential before/after CD4 counts for the male patient (pale green) and the female patient (pale pink) are also highlighted on the table.

Discussion/conclusion Reassuringly, statistical analysis showed very close correlation between the two methods, apart from the two odd results. Previous and subsequent counts in these two patients were normal, as expected. Twenty years ago only the percentage was available so absolute number was calculated using the simple method: lymphocyte count $\times$ CD4\%. As usual in medicine, no methodology is perfect. Unexpected results should be questioned and, if necessary, repeated, especially if important therapeutic decisions depend on them.

\section{P044 PEP/PEPSE REAUDIT - WHOSE NOTES ARE THEY ANYWAY? - THE DATA PROTECTION ACT RESTRICTING CLINICAL AUDIT}

Rebecca Thomson-Glover*, John Evans-Jones. Countess of Chester NHS Foundation Trust/ East Cheshire NHS Trust, Chester, UK

\subsection{6/sextrans-2016-052718.98}

Background/introduction Post Exposure Prophylaxis (PEP) is prescribed to patients presenting with a history of occupational or sexual exposure to HIV infection. The British Association for Sexual Health and HIV (BASHH) published new clinical guidelines on PEP following Sexual Exposure (PEPSE) in 2015. 